\title{
A study to compare forward functional reach between normal and obese subjects
}

\author{
Rajkumar Krishnan Vasanthi ${ }^{1}$, Sivakumar Ramachandran ${ }^{2}$ \\ ${ }^{1}$ Clinical Coordinator, INTI International University, Malaysia \\ ${ }^{2}$ Principal College of Physiotherapy, Sri Ramachandra University College Chennai, India
}

\begin{abstract}
Objective: The aim of the study was to determine the influence of body mass index (BMI) in obese individuals on functional reach.

Methods: Obese subjects whose BMI was $\geq 30 \mathrm{~kg} / \mathrm{m}^{2}$ and normal subjects with BMI $18.5-24.9 \mathrm{~kg} / \mathrm{m}^{2}$ were considered for this study. They were screened for eligibility to participate in the study and they were grouped into obese and normal of 50 subjects each. The subjects were asked to lean forward with 90 degrees of shoulder flexion, taking precautions not to rotate the trunk, and to flex the knees without raising the heels. The distance reached in this position was marked as the final reference. The average of three trails of the initial and final reference points was noted as the reading.

Results: A Pearson correlation between increasing BMI and forward functional reach (FFR) in obese individuals was statistically significant (Table 2) whereas a correlation between increasing height and forward functional reach in obese individuals was statistically not significant (Table 3). The results reveal that as the $\mathrm{BMI}$ increases in obese individuals the FFR reduces.
\end{abstract}

Conclusion: Obese individuals show less forward functional reach when compared to normal subjects.

Key words: forward functional reach, balance, body mass index, obese.

\section{Introduction}

Obesity is recognized as a major health problem in many parts of the world and the incidence of the condition is escalating at an alarming rate. Obesity has reached epidemic proportions globally, with more than 1.9 billion adults overweight and at least 650 million clinically obese and has been considered a major contributor to the global burden of chronic diseases and disability [1]. Moreover, in 2016 39\% of adults aged 18 years and over were overweight and $13 \%$ were obese. Obesity is a complex condition with serious social and psychological dimensions, affecting virtually all ages and socioeconomic groups [1]. The prevalence of overweight and obesity is commonly assessed by using a body mass index (BMI), defined as the weight in kilograms divided by the square of the height in meters $\left(\mathrm{kg} / \mathrm{m}^{2}\right)$. The BMI between $25 \mathrm{~kg} / \mathrm{m}^{2}$ and $29.9 \mathrm{~kg} / \mathrm{m}^{2}$ is defined as overweight and that $\geq 30 \mathrm{~kg} / \mathrm{m}^{2}$ as obesity (WHO) [1].

In spite of significant advances in the knowledge and understanding of the multi-factorial nature of obesity, many questions regarding the specific consequences of the condition remain unanswered. In particular, there is a relative dearth of information pertaining to the functional limitations imposed by overweight and obesity. To date, only few studies have mainly focused on the effect of obesity on the temporospatial characteristics of walking, plantar foot pressures, muscular strength and, to a lesser extent on postural balance [2]. A better appreciation of implications of increased levels of body adiposity on movement capabilities of the obese would afford a greater opportunity to 
provide meaningful support in preventing, treating and managing the condition and its sequelae [2].

Most studies investigating postural control in the obese have employed cross-sectional study designs and have not considered the potentially confounding effects on physical activity (WHO 1998). Obese persons (particularly those with an abnormal distribution of body fat in the abdominal area) may be at a higher risk of falling than lightweight individuals; moreover, obesity has been found to be associated with a greater area of sway [3]. A decrease in balance stability is strongly correlated with an increase in body weight, suggesting that the body weight may be an important risk factor for falling [4]. According to another study, extremely obese individuals have inadequate postural stability that could however be improved by a few sessions of balance training with a body weight reduction programme and balance improvement is an important goal of rehabilitation likely to reduce the propensity of overweight individuals to fall while performing everyday activities [5]. During experimental solicitations, obesity has significatively influenced the postural control of teenagers. Beside systematic statistical differences, a decrease in balance capacities of obese subjects has been observed [6].

Few studies in obese individuals have included balance trainings as part of an overall exercise programme [7]. Metabolic inefficiency of excess fat is thought to be a primary cause of decreased physical activity in the obese population as well as biomechanical inefficiency of movement and impaired stability [8].

According to many researches obese individuals have reduced balance and increased chances of fall. Exercises combined weight reduction regimens reduce disability and improve daily activities.

The functional reach test has proved to be useful in detecting balance impairment and changes in balance impairment overtime. The above test is a portable, inexpensive, reliable, precise, and reasonable clinical approximator of the margins of stability. Normative values of the functional reach test for different age groups are available [9]. There are no literature studies/data on impact of obesity on functional reach test scores. As there are studies stating that obesity impairs balance strategies, this study was intended to analyse the effect of obesity on functional reach.

\section{Methods}

Study design and population

Upon institutional ethical clearance, the subjects were recruited and screened for eligibility to participate in the study and they were grouped into obese and normal of 50 subjects each. The purpose of the study was explained to each subject who signed the informed consent. Obese subjects whose BMI was $\geq 30 \mathrm{~kg} / \mathrm{m}^{2}$ and normal subjects whose BMI was 18.5 to $24.9 \mathrm{~kg} / \mathrm{m}^{2}$ were considered for this study. To participate in the study, selected subjects had to meet the following criteria.

\section{Inclusion criteria}

Age group of 20-40 years

$\mathrm{BMI} \geq 30 \mathrm{~kg} / \mathrm{m}^{2}$ [Obese]

BMI 18.5 to $24.5 \mathrm{~kg} / \mathrm{m}^{2}$ [Normal]

\section{Exclusion criteria}

Any deformities in the spine, upper and lower extremity

History of vestibular problems

History of chronic alcoholism

History of cerebrovascular accidents and neurological problems resulting in balance impairments

Restricted range of motion in the upper and lower extremities

History of diabetes mellitus

History suggesting arthritis in the upper and lower extremities 


\section{Procedure}

The functional reach test (FRT) was used to measure the balance of selected subjects. The functional reach calibrator is designed to have a level platform, perpendicular to which, a heightmeasuring device [vertical scale] is vertically fixed. A sliding horizontal scale, which can be adjusted to the shoulder height, is fixed to the vertical scale to determine the functional reach.

Each subject was allowed to stand on the platform and heights are measured using the vertical scale as a standard. Footmarks were made on the platform to standardize the standing position. The sliding horizontal scale was adjusted to the shoulder level of the subjects. The subjects were asked to flex the bilateral shoulder to 90 degrees with their forearm pronated, finger flexed to make a fist with the $3^{\text {rd }}$ metacarpal head was marked as an initial reference on the sliding horizontal scale. Subsequently, the subjects were asked to lean forward, taking precautions not to rotate the trunk, and flex the knees without raising the heels. The distance reached in this position was marked as the final reference. A trail was given before the final reading. The average of three trails of the initial and final reference points was noted as the reading. The forward reach scores were used for statistical analysis.

\section{Results}

The results of forward functional reach distance for both obese and normal subjects were individually analyzed by using the statistical package for social sciences (SPSS) for Windows.

The mean differences between the obese and normal forward functional reaches were calculated and compared using the independent samples t-test; the difference between forward reach in obese and normal individuals was found to be statistically significant (Table 1).
Table 1. Comparison of forward functional reach between obese and normal individuals

\begin{tabular}{|c|c|c|c|c|c|c|}
\hline \multirow{2}{*}{$\begin{array}{l}\text { outcome } \\
\text { measure }\end{array}$} & \multicolumn{2}{|c|}{ Obese } & \multicolumn{2}{|c|}{ Normal } & \multirow[b]{2}{*}{$\mathrm{t}$ - test } & \multirow[b]{2}{*}{$\mathrm{p}<0.005$} \\
\hline & $\begin{array}{l}\text { mean } \\
\text { value }\end{array}$ & SD & $\begin{array}{l}\text { mean } \\
\text { value }\end{array}$ & SD & & \\
\hline $\begin{array}{l}\text { functional } \\
\text { reach } \\
\text { (inch) }\end{array}$ & 10.84 & 0.92 & 15.15 & 1.14 & 20.756 & $\begin{array}{l}\text { signifi- } \\
\text { cant }\end{array}$ \\
\hline
\end{tabular}

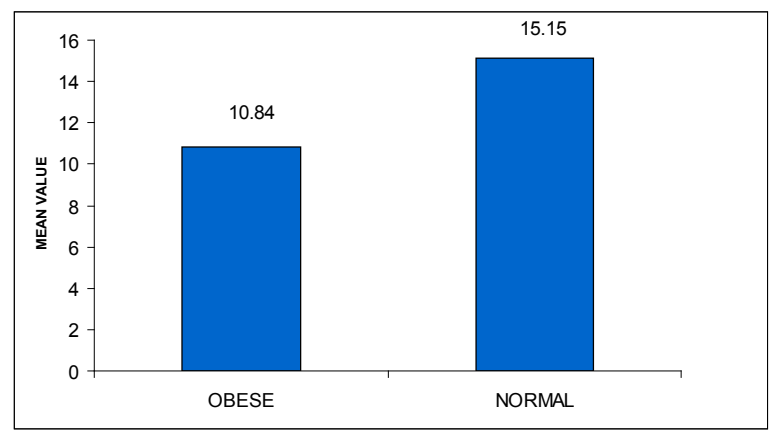

Fig. 1. Mean of forward functional reach in obese versus normal individuals

The Pearson correlation between increasing $\mathrm{BMI}$ and forward functional reach [FFR] in obese individuals was statistically significant (Table 2).

Table 2. Correlation between BMI and functional reach in obese individuals

\begin{tabular}{|c|c|c|c|c|}
\hline variables & Mean & SD & $\mathrm{r}$ & $\mathrm{p}<0.005$ \\
\hline BMI $\left(\mathrm{kg} / \mathrm{m}^{2}\right)$ & 32.63 & 2.57 & & \\
\cline { 1 - 1 } $\begin{array}{c}\text { functional } \\
\text { reach (inch) }\end{array}$ & 10.84 & 0.92 & -0.532 & significant \\
\hline
\end{tabular}

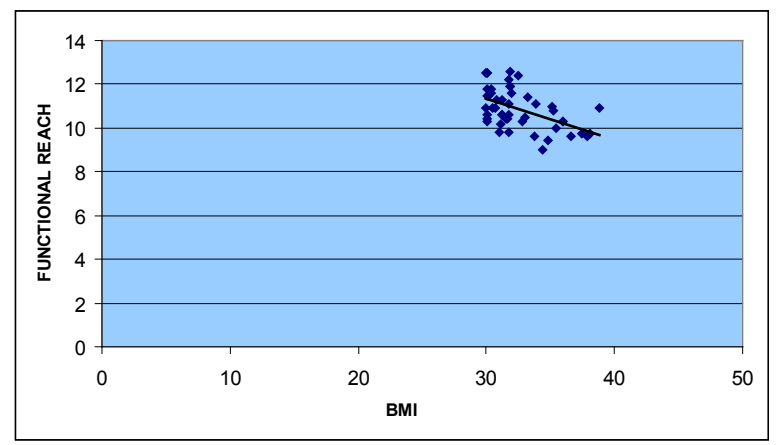

Fig. 2. The Pearson correlation between MBI and functional reach in obese individuals

whereas the correlation between increasing height and FFR in obese individuals was statistically non-significant (Table 3). 
Table 3. Correlation between height and functional reach in obese individuals

\begin{tabular}{|c|c|c|c|c|}
\hline variables & Mean & SD & $\mathrm{r}$ & $\mathrm{p}<0.005$ \\
\hline height $\left(\mathrm{m}^{2}\right)$ & 2.82 & 0.32 & \multirow{2}{*}{0.122} & $\begin{array}{c}\text { not } \\
\text { significant }\end{array}$ \\
\cline { 1 - 3 } $\begin{array}{c}\text { functional } \\
\text { reach (inch) }\end{array}$ & 10.84 & 0.92 & & \\
\hline
\end{tabular}

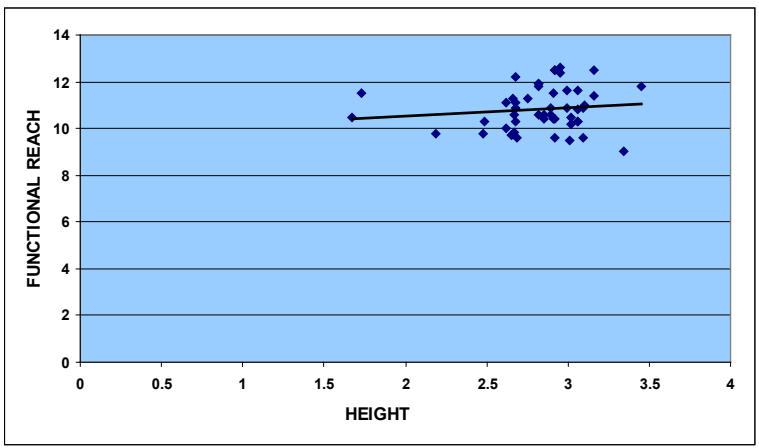

Fig. 3. The Pearson correlation between height and functional reach in obese individuals

On the other hand, in normal subjects, the Pearson correlation between BMI and FFR was statistically non-significant (Table 4)

Table 4. Correlation between BMI and functional reach in normal subjects

\begin{tabular}{|c|c|c|c|c|}
\hline variables & Mean & SD & $\mathrm{r}$ & $\mathrm{p}<0.005$ \\
\hline height $\left(\mathrm{m}^{2}\right)$ & 22.64 & 1.26 & \multirow{2}{*}{-0.118} & $\begin{array}{c}\text { not } \\
\text { significant }\end{array}$ \\
\cline { 1 - 3 } $\begin{array}{c}\text { functional } \\
\text { reach (inch) }\end{array}$ & 15.15 & 1.14 & - & \multicolumn{2}{|c}{} \\
\hline
\end{tabular}

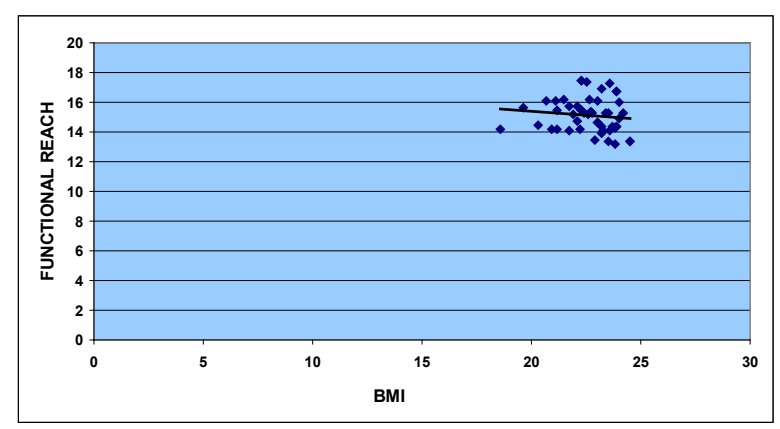

Fig. 4.The Pearson correlation between BMI and functional reach in normal subjects

whereas the correlation between height and FFR was significant (Table 5).
Table 5. Correlation between height and functional reach in normal subjects

\begin{tabular}{|c|c|c|c|c|}
\hline variables & Mean & SD & $\mathrm{r}$ & $\mathrm{p}<0.005$ \\
\hline height $\left(\mathrm{m}^{2}\right)$ & 2.88 & 0.23 & \multirow{2}{*}{0.616} & significant \\
\cline { 1 - 3 } $\begin{array}{c}\text { functional } \\
\text { reach (inch) }\end{array}$ & 15.15 & 1.14 & .616 & \\
\hline
\end{tabular}

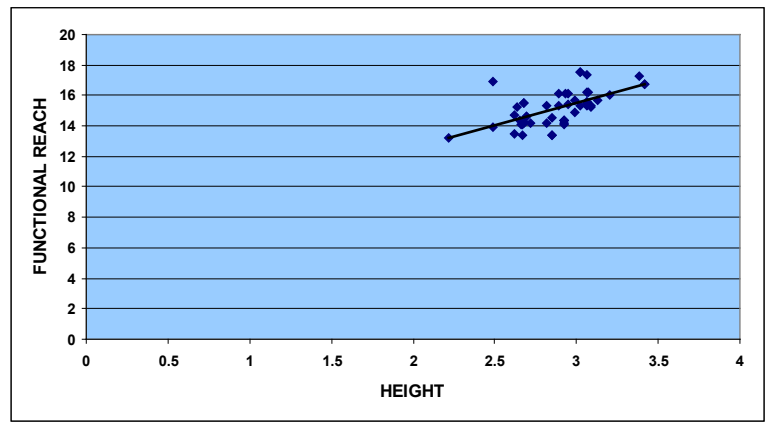

Fig. 5. The Pearson correlation between height and functional reach in normal subjects

The values obtained were further statistically analyzed showing that the difference in FFR between the BMI ranges in obese individuals was more significant (Table 6),

Table 6. Comparison of BMI range and forward functional reach in obese individuals

\begin{tabular}{|c|c|c|}
\hline $\begin{array}{c}\text { BMI range } \\
\left(\mathrm{kg} / \mathrm{m}^{2}\right)\end{array}$ & $\begin{array}{c}\text { number of } \\
\text { subjects }\end{array}$ & $\begin{array}{c}\text { functional reach } \\
\text { (inch) }\end{array}$ \\
\hline $30-32$ & 31 & 11.1 \\
\hline $32-34$ & 6 & 10.8 \\
\hline $34-36$ & 7 & 10.1 \\
\hline$>36$ & 6 & 9.8 \\
\hline
\end{tabular}

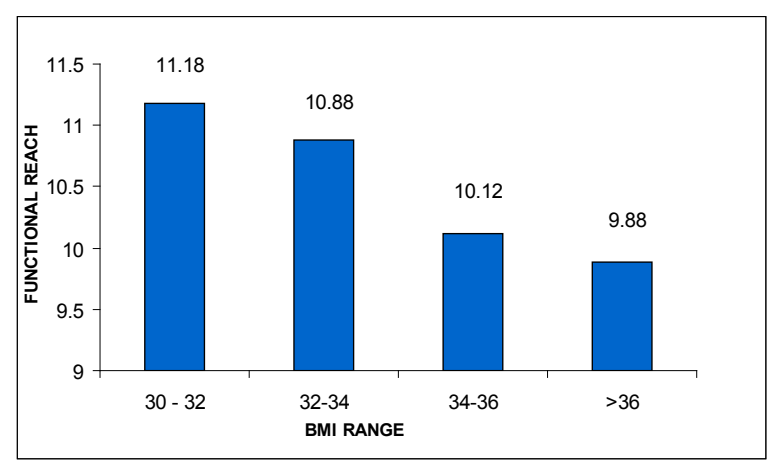

Fig. 6. The BMI range versus forward functional reach in obese individuals

i.e. 0.4 inch for every $2 \mathrm{~kg} / \mathrm{m}^{2}$ rise in BMI; in normal subjects the BMI range of $20-24 \mathrm{~kg} / \mathrm{m}^{2}$ was considered for further analysis between BMI and FFR. The other groups with the BMI $<20$ and 
$>24$ were not considered for analysis because of their very low number of subjects. Analysis of the considered group $\left[20-24 \mathrm{~kg} / \mathrm{m}^{2}\right]$ demostrated a difference of 0.1 inch FFR (Table 7).

Table 7. Comparison of BMI range and forward functional reach in normal subjects

\begin{tabular}{|c|c|c|}
\hline $\begin{array}{c}\text { BMI range (kg/ } \\
\left.\mathrm{m}^{2}\right)\end{array}$ & $\begin{array}{c}\text { number of } \\
\text { subjects }\end{array}$ & $\begin{array}{c}\text { functional } \\
\text { reach(inch) }\end{array}$ \\
\hline $18-20$ & 2 & 14.9 \\
\hline $20-22$ & 10 & 15.1 \\
\hline $22-24$ & 35 & 15.2 \\
\hline$>24$ & 3 & 14 \\
\hline
\end{tabular}

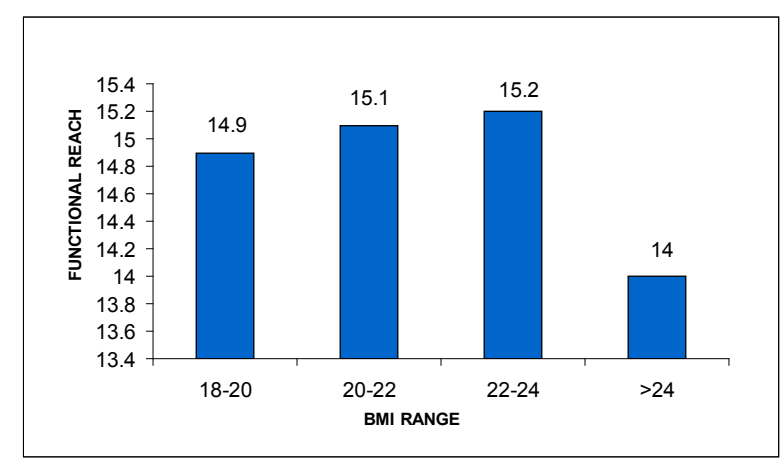

Fig. 7. BMI range and forward functional reach in normal subjects

Thus, the results revealed that as the BMI increased in obese individuals, the FFR decreased.

\section{Discussion}

According to the WHO, obesity is a complex condition with serious social and psychological dimensions, affecting virtually all ages and socioeconomic groups; moreover, it is a major contributor to the global burden of chronic diseases and disabilities [1].

Currently more than 1.9 billion adults are overweight and at least 600 million of them are clinically obese [1]. The main finding of the present study was that varying body mass index influenced the balance. Obese individuals showed lower scores of forward functional reach when compared to normal subjects. Statistical analysis using the SPSS data proved that there was a highly significant difference between normal and obese groups in performing the forward functional reach test $[\mathrm{P}<0.001]$, which supported the hypothesis of our study.

Decreased functional reach distances could be attributed to decreased lower extremity muscle activity due to reduced oxidative capacity resulting in decreased force and endurance, as stated by Corbeil et al. [10]. This assumption has also been supported by Hulens et al., demonstrating reduced muscle activity in lower extremities due to altered metabolic state in obesity [11]. The body size and shape of individuals have affected the static postural stability by altering the location of the centre of gravity as reported by Fregly et al. [12]. While analysing the normative values of forward functional reach, Duncan et al. (1990) considered only age and height as factors [9].

In our study, correlations between height, BMI and functional reach in the adult population aged 20-40 years were analyzed.

Furthermore, there was an inverse relationship between BMI and FFR in obese individuals, i.e. increased BMI was associated with significantly reduced FFR

Further analysis of the study findings demonstrated that the height of obese individuals was not a statistically significant factor when compared to BMI. Moreover, the correlation between BMI and FFR in normal individuals was not found to be statistically significant, whereas the correlation between height and FFR was found significant.

Thus, height is a significant factor affecting FFR of subjects with normal BMI; otherwise, in obese individuals BMI is a significant factor influencing their FFR.

In this study population, subjects with the BMI range of $20-24 \mathrm{~kg} / \mathrm{m}^{2}$ were considered for further analysis between BMI and FFR, as they constituted the maximum number of subjects in the normal BMI study population. The other groups with BMI 
$<20$ and $>24$ were not considered for analysis as their number was very low. Analysis of the considered group $\left[20-24 \mathrm{~kg} / \mathrm{m}^{2}\right]$ showed a 0.1 -inch difference in FFR. In obese individuals, the differences in FFR between the BMI ranges were more significant, i.e. 0.4 inch for every $2 \mathrm{~kg} / \mathrm{m}^{2}$ rise in BMI. Noteworthy, the limitation of this finding was that the number of subjects in each BMI range was not constant.

The study results can be applied in obese individuals undergoing neurological rehabilitation for forward functional reach as balance outcome measures.

Since Duncan et al. [9] studied normal individuals for normative values of forward functional reach, it could be difficult to compare their results with obese patients undergoing neurological rehabilitation. Therefore, it became evident that the relationship between obese and normal subjects had to be found. In obese patients, it would be unrealistic to use the normative value, suggested by Duncan et al. [9], to be achieved in balance rehabilitation. Our findings proved the above statement. If the normative value has been standardized for a large population of these individuals, it could be applied to neurological rehabilitation programmes to set a realistic goal.

In future studies, this limitation should be considered and standard values can be obtained for a large population, including overweight subjects, which were not considered in our study.

\section{Conclusions}

Obese individuals show lower scores of forward functional reach when compared to normal subjects. As their body mass index increases, the forward functional reach decreases.

\section{Funding}

This research did not receive any specific grant from funding agencies in the public, commercial, or not-for-profit sectors.

\section{Acknowledgement}

Special thanks to my supervisor and my friend for their guidance and unlimited support.

\section{References}

1. WHO 2017. http//www.who.int/mediacentre/ factsheets/fs311/ en/index.html.

2. S. C. Wearing, E. M. Hennig, N. M. Byrne, J. R. Steele and A. P. Hills: The biomechanics of restricted movement in adult obesity. Obesity Reviews Volume 7 Page 13 - February 2006.

3. Ledin T, Odkvist LM. Effects of increased inertial load in dynamic and randomized perturbed posturography. Acta Otolaryngol 1993; 113:249-52.

4. Hue O, Simoneau M, Marcotte J, Berrigan F, Dore J, Marceau P, Marceau S, Tremblay A, Teasdale N. Body weight is a strong predictor of postural stability. Gait Posture. Jun;26(1):32-8.

5. Maffiuletti NA, Agosti F, Proietti M, Riva D, Resnik M, Lafortuna CL, Sartorio A. Postural instability of extremely obese individuals improves after a body weight reduction program entailing specific balance training. Journal Endocrinology Investigation.2005 Jan; 28(1):2-7.

6. Bernard PL, Geraci M, Hue O, Amato M, Seynnes $\mathrm{O}$, Lantieri D. Influence of obesity on postural capacities of teenagers: Preliminary study. Ann Readapt Med Phys. 2003 May; 46(4):184-90.

7. Clark, Kristine N. M.S., RCEP. Balance and Strength Training for Obese Individuals. ACSM'S Health \& Fitness Journal. 2004; 8(1): 14-20.

8. Katch V, Becque MD, Marks C, Moorehead $\mathrm{C}$, Rocchini A. Oxygen uptake and energy output during walking of obese male and female adolescents. Am J Clin Nutr 1998; 47:26-32.

9. Duncan PW, Weiner DK, Chandler J, Studenski S. Functional reach: A clinical measure of balance. J Gerontol. 1990 Nov;45(6):M192-7.

10. Corbeil P, Simoneau M, Rancourt D, Tremblay A, Teasdale N. Increased risk for falling associated with obesity: mathematical modeling of postural control. IEEE Trans Neural Syst Rehabil Eng 2001; 9: $126-136$

11. Hulens M, Vansant G, Lysens R, Claessens AL, Muls E, Brumagne S. Study of differences in peripheral muscle strength of lean versus obese women; An allometric approach. Int J Obes Relat Metab Disord 2001; 25: 676-681.

12. Fregly AR, Oberman A, Graybiel A, Mitchell RE. Thousand-aviator study: Nonvestibular 
contributions to postural equilibrium functions.

Aero Med 1968; 39: 33-37.

\section{Corresponding author address:}

Rajkumar Krishnan Vasanthi

Lecturer/ Clinical Coordinator

INTI International University

Nilai - 71800, Negeri Sembilan,

Malaysia.

Email: rajkumarhari@yahoo.co.in

rajkumar.krishnan@newinti.edu.my 